\title{
Longitudinal association of gonorrhea and bacterial vaginosis with repeat chlamydia diagnoses among U.S. Army women: a retrospective cohort analysis
}

\author{
Christian T. Bautista ${ }^{1 *} \mathbb{D}$, Eyako K. Wurapa ${ }^{2}$, Warren B. Sateren ${ }^{3}$, Bruce P. Hollingsworth ${ }^{1}$ and Jose L. Sanchez ${ }^{4}$
}

\begin{abstract}
Background: Historically, sexually transmitted infections have affected the health of the U.S. military. To determine whether gonorrhea, bacterial vaginosis, genital herpes, and trichomoniasis are predictors of repeat chlamydia diagnoses among U.S. Army women, medical data reported into the Defense Medical Surveillance System during the 2006-2012 period were analyzed.

Methods: For all inpatient and outpatient medical records, the first and second International Classification of Diseases, version 9 (ICD-9) diagnostic positions were reviewed for each chlamydia case to determine the occurrence of repeat diagnoses. The Andersen-Gill regression model, an extension of the Cox model for multiple failure-time data, was used to study associations between predictors and repeat chlamydia diagnoses.

Results: Among 28,201 women with a first chlamydia diagnosis, 5145 (18.2\%), 1163 (4.1\%), 267 (0.9\%), and 88 (0.3\%) had one, two, three, and four or more repeat diagnoses, respectively. Overall, the incidence of repeat chlamydia was 8.31 cases per 100 person-years, with a median follow-up time of 3.39 years. Gonorrhea (hazard ratio $(H R)=1.58,95 \%$ Cl: 1.44-1.73) and bacterial vaginosis ( $H R=1.40,95 \% \mathrm{Cl}: 1.09-1.79)$ were significant predictors for repeat chlamydia. These estimated hazard ratios were attenuated, but remained significant, after controlling for age, race/ethnicity, marital status, and military rank. No significant association was found for genital herpes ( $H R=1.13,95 \% \mathrm{Cl}$ : 0.55-2.29) and trichomoniasis ( $H R=1.43,95 \% \mathrm{Cl}: 0.43-4.68)$.

Conclusions: This large cohort study suggests that gonorrhea and bacterial vaginosis were associated with repeat chlamydia diagnoses among U.S. Army women. These findings can be used in formulating new interventions to prevent repeat chlamydia diagnoses.
\end{abstract}

Keywords: Gonorrhea, Bacterial vaginosis, Chlamydia, Sexually transmitted infection, Military

\section{Background}

In the U.S. civilian population, chlamydia is a commonly diagnosed sexually transmitted infection (STI) [1]. In 2014, approximately 1.4 million cases of chlamydia were reported, of which, most occurred among young people and women. Chlamydia also represents a significant health problem for the U.S. military. According to the Armed Forces Health Surveillance Branch, during the period 2000-2012, 198,274 chlamydia diagnoses were reported among service

\footnotetext{
* Correspondence: cbautistat@gmail.com; m.bautista@lancaster.ac.uk 'Division of Health Research, Lancaster University, Lancaster, UK Full list of author information is available at the end of the article
}

members (SMs) [2]. Over $44 \%$ of these diagnoses occurred in women SMs and 39\% in African-American personnel.

In women, chlamydia can be associated with reproductive complications such as pelvic inflammatory disease and ectopic pregnancy. However, the risk of such complications is much higher in women with repeat chlamydia infection [3]. According to the literature, no single behavioral risk factor has been consistently reported to predispose to repeat infection [3, 4]. In part, this is because the mechanisms underlying repeat infections are complex in the field of STIs. In addition, in most studies of repeat chlamydia, the event of interest has been time to the first repeat infection,

(C) The Author(s). 2018 Open Access This article is distributed under the terms of the Creative Commons Attribution 4.0 International License (http://creativecommons.org/licenses/by/4.0/), which permits unrestricted use, distribution, and 
ignoring the subsequent infections. Therefore, those studies are suboptimal to address the true burden of repeat chlamydia.

The literature also indicates a high rate of repeat chlamydia among U.S. military women. During 1994-1998, the rate of repeat chlamydia among U.S. Army women was 65.79 per 1000 person-years (py) [5]. In another study conducted at Fort Bragg (the largest U.S. Army base worldwide in terms of population) during 20052010, the rate of repeat chlamydia in women was 161.9 per 1000 py [6]. Recently, it has been estimated that, during 2010-2014, the rate of repeat chlamydia was 116.3 per 1000 py among U.S. military women [7]. Although these studies offer insights into the epidemiology of repeat chlamydia in the U.S. military, only risk factors, such as younger age, black race, and single marital status have been studied; other risk factors, such as gonorrhea, have not been studied [8].

Given the paucity of studies examining whether other STIs and common gynecological disorders represent potential risk predictors for repeat chlamydia in the U.S. military, the aim of this retrospective cohort study was to characterize whether gonorrhea, genital herpes, trichomoniasis or bacterial vaginosis (BV) were associated with repeat chlamydia among female SMs. The findings can be applied to guide further targeted STI research and to implement new prevention efforts to reduce the burden of chlamydia in U.S. Army women.

\section{Methods}

\section{Data source}

This study used personnel and medical data registered in the Defense Medical Surveillance System (DMSS). The DMSS is the central health surveillance system for recording and monitoring the health of the U.S. Armed Forces. This surveillance system (over 2 billion medical records by 2015) collects data regarding all medical encounters (in-patient and out-patient), including immunizations, reportable events, and human immunodeficiency virus (HIV) test results. It also collects personnel demographic and deployment data for service members from the day they enter the service until the day they leave. At clinic and hospital sites, the medical staff input data from the patient medical charts into the Armed Forces Health Technology Application, which is then transferred to the DMSS. Using the International Classification of Diseases, version 9 (ICD-9), for each medical event, a maximum of eight codes can be registered. The first two codes register the primary reasons for the visit. Details about the DMSS have been published elsewhere [9].

According to a survey of the U.S. Army laboratories (31 in the U.S. and 7 in Europe and Asia), from the 255,509 C. trachomatis specimens collected in 2007, $79 \%$ were tested using nucleic acid amplification tests (NAATs)
[10]. This survey also revealed that NAATs followed by culture were the most common methods utilized to detect $N$. gonorrhoeae. Similar findings were recently published by Leamer et al [11]. In the U.S. Army, diagnosis of BV and trichomoniasis is usually based on the four Amsel criteria and wet mount examination, respectively.

\section{Study design and population}

The study population consisted of women personnel who were on active duty in the U.S. Army for any period between January 1, 2006, and December 31, 2012. All women with a chlamydia diagnosis during the study period, and without a chlamydia diagnosis prior to January 1, 2006, were selected. The criteria for a diagnosis of chlamydia was based on the ICD-9 diagnostic codes. For chlamydia diagnosis, the ICD-9 codes were 099.41 or 099.5. For all inpatient and outpatient medical records, the first and second diagnostic position were reviewed for each chlamydia case to determine the occurrence of repeat diagnoses until the end of the study period or termination of military service. Given than NAATs can detect residual bacterial deoxyribonucleic acid for up to 3 weeks after therapy [12], a repeat chlamydia diagnosis was defined as one which occurred 30 days after the previous diagnosis. The decision to use 30 days for determining repeat chlamydia also followed the recent Centers for Disease Control and Prevention (CDC) guidelines [13].

\section{Study variables}

Demographic variables included age, race/ethnicity (white, African-American, other), educational level (no high school, high school or higher), marital status (single, married, other), and military rank (officer, enlisted). To determine whether other STIs or common gynecological disorders increased the hazard of repeat chlamydia diagnoses, the DMSS database was searched using ICD-9 codes for gonorrhea $(098.0 \times, 098.1 \times, 098.4 \times$, or $098.8 \times)$, BV (616.10), genital herpes simplex virus (054.1), and trichomoniasis (131.9). Women with these ICD-9 codes before or at the time of their first chlamydia diagnosis were excluded from analysis. The rationale for this exclusion criteria was to exclude women SMs with previous infections from the study population, to prevent confusion of the results.

\section{Statistical analyses}

The chi-square test was used to compare the percentage of gonorrhea and BV among women with or without repeat chlamydia diagnoses. The rate of repeat chlamydia diagnoses was estimated by the number of repeat diagnoses divided by the total follow-up period per 100 py. To determine the association between repeat chlamydia diagnoses and other STIs and BV, the counting process (multiple observations are created for each individual) of the Andersen-Gill regression model was applied [14]. 
This model, which is an extension of the Cox regression method for analyzing data with repeated events, assumes that the correlation among events is induced by measured covariates, which is the aim of this study [15]. In the regression models, gonorrhea, BV, genital herpes, and trichomoniasis were treated as time-varying variables, whereas demographic and military characteristics were treated as fixed variables. The time scale was days and the time-varying variables were updated at the respective entry times. Associations were expressed in terms of hazard ratios $(H R)$ with $95 \%$ confidence intervals $(95 \% \mathrm{CI})$. All analyses were performed using Stata version 13.1 (Stata Corporation, College Station, TX).

\section{Results}

During the study period, 37,419 women SMs with a first chlamydia diagnosis were registered into the DMSS. Of these, 9218 (25\%) were excluded due to the exclusion criteria. Among the eligible population $(n=28,201,75 \%)$ as shown in Table 1, 89\% of women SMs were enlisted members, $84 \%$ were $17-24$ years old ( mean $=21.6$ years), $73 \%$ were single, and $43 \%$ were white. Additionally, most of the population had a high school or higher education (93\%).

The median follow-up was 3.39 years (interquartile range $(I Q R)=2.07-5.26$ years). During the follow-up period, $6663(23.6 \%)$ women had at least one repeat chlamydia diagnosis. Of these, 5145 (18.2\%), 1163 (4.1\%), and 355 (1.3\%) had one, two, and three or more repeat diagnoses, respectively. Overall, the rate of repeat chlamydia diagnoses was 8.31 cases (95\% CI: 8.14-8.49) per 100 py. Higher repeat rates occurred among those women who were younger (17-19 years old), of African-Americans race/ethnicity, in the enlisted ranks, and single (Table 1).

Among 28,201 women personnel, the percentage of gonorrhea, BV, genital herpes, and trichomoniasis was $2.6 \%(n=735), 0.5 \%(n=150), 0.1 \%(n=19)$, and $0.04 \%$ $(n=12)$, respectively. For women with repeat chlamydia diagnoses, gonorrhea and BV percentages were significantly higher compared to women without repeat chlamydia diagnoses (Table 2). Significant differences were also noted between the women with and without repeat chlamydia diagnoses in terms of age group, race/ethnicity, marital status, and military rank subcategories. Regarding genital herpes and trichomoniasis, their percentages were $0.15 \%(n=10)$ and $0.12 \%(n=8)$, respectively, for women with repeat chlamydia diagnoses, and $0.04 \%(n=9)$ and $0.02 \%(n=4)$, respectively, for women without repeat chlamydia diagnoses. Due to the small number of women with a diagnosis of genital herpes or trichomoniasis, data by subcategories are not shown.

According to the Andersen-Gill regression analysis, gonorrhea $(H R=1.58,95 \% \mathrm{CI}: 1.44-1.73)$ and $\mathrm{BV}(H R=1.40$, 95\% CI: 1.09-1.79) were significantly associated with repeat chlamydia diagnoses (Table 3). After controlling for age (in years), the adjusted $H R$ s for gonorrhea $(H R=1.47)$ and $\mathrm{BV}$ $(H R=1.32)$ were attenuated but remained significant (Model 1). Similar adjusted HR were obtained after controlling for age, race/ethnicity, marital status, and military rank

Table 1 Demographic characteristics and repeat chlamydia diagnoses among U.S. army women

\begin{tabular}{|c|c|c|c|c|c|c|}
\hline \multirow[t]{2}{*}{ Item } & \multirow{2}{*}{$\begin{array}{l}\text { Women with initial } \\
\text { diagnosis of chlamydia }(n)\end{array}$} & \multicolumn{3}{|c|}{ Women with repeat diagnoses of chlamydia ( $n(\%))$} & \multicolumn{2}{|c|}{ Incidence rate of repeat chlamydia diagnoses ${ }^{c}$} \\
\hline & & One & Two & Three or more & Cases per 100 py $(n)$ & $95 \% \mathrm{Cl}$ \\
\hline All women & 28,201 & $5145(18.2)$ & $1163(4.1)$ & $355(1.3)$ & 8.31 & $8.14,8.49$ \\
\hline \multicolumn{7}{|l|}{ Age group (year) } \\
\hline $17-19$ & 8540 & $1959(22.9)$ & $532(6.2)$ & $179(2.1)$ & 11.56 & $11.19,11.95$ \\
\hline $20-24$ & 15,319 & $2687(17.5)$ & $558(3.6)$ & $159(1.0)$ & 7.73 & $7.50,7.96$ \\
\hline$>=25$ & 4342 & $499(11.5)$ & $73(1.7)$ & $17(0.4)$ & 4.15 & $3.86,4.47$ \\
\hline \multicolumn{7}{|l|}{ Race/Ethnicity } \\
\hline White & 12,046 & $1983(16.5)$ & $364(3.0)$ & $95(0.8)$ & 7.25 & $6.99,7.51$ \\
\hline African-American & 8605 & $1783(20.7)$ & $480(5.6)$ & $166(1.9)$ & 9.80 & $9.47,10.13$ \\
\hline Other $^{\mathrm{a}}$ & 7112 & 1304 (18.3) & $304(4.3)$ & $84(1.2)$ & 8.15 & $7.82,8.50$ \\
\hline \multicolumn{7}{|l|}{ Marital status } \\
\hline Single & 20,487 & 3965 (19.3) & $924(4.5)$ & $282(1.4)$ & 8.87 & $8.66,9.09$ \\
\hline Married & 6349 & 981 (15.4) & $210(3.3)$ & $65(1.0)$ & 7.08 & $6.74,7.43$ \\
\hline Other $^{\mathrm{b}}$ & 1354 & $197(14.5)$ & $29(2.1)$ & $8(0.6)$ & 5.41 & $4.81,6.08$ \\
\hline \multicolumn{7}{|l|}{ Military rank } \\
\hline Enlisted & 25,125 & 4797 (19.1) & $1120(4.5)$ & $346(1.4)$ & 9.02 & $8.83,9.22$ \\
\hline Officers & 3076 & $348(11.3)$ & $43(1.4)$ & $9(0.3)$ & 3.45 & $3.15,3.78$ \\
\hline
\end{tabular}

Cl Confidence interval, Denominators may vary due to missing data. ${ }^{a}$ Other: Hispanic, American Indian/Alaskan Native, Asian/Pacific Islander, and others. ${ }^{\mathrm{b}}$ Other: Divorced, widowed, and others. ${ }^{C}$ Rate reported as per 100 person-years 
Table 2 Percentage of gonorrhea and bacterial vaginosis among women with or without repeat chlamydia diagnoses among U.S. Army women (\%)

\begin{tabular}{|c|c|c|c|c|c|c|}
\hline \multirow[t]{2}{*}{ Feature } & \multicolumn{3}{|c|}{ Women with repeat chlamydia diagnoses } & \multicolumn{3}{|c|}{ Women without repeat chlamydia diagnoses } \\
\hline & Gonorrhea $^{c}$ & $\mathrm{BV}^{\mathrm{c}}$ & $P$ value & Gonorrhea $^{c}$ & $\mathrm{BV}^{\mathrm{c}}$ & $P$ value \\
\hline All women & $6.9(459 / 6663)$ & $1.3(88 / 6663)$ & $<0.001$ & $1.3(276 / 21,538)$ & $0.3(62 / 21,538)$ & $<0.001$ \\
\hline \multicolumn{7}{|l|}{ Age group (year) } \\
\hline $17-19$ & $8.3(221 / 2670)$ & $1.3(34,2670)$ & $<0.001$ & $1.7(98 / 5870)$ & $0.3(20 / 5870)$ & $<0.001$ \\
\hline $20-24$ & $6.3(213 / 3404)$ & $1.3(43 / 3404)$ & $<0.001$ & $0.5(148 / 11,915)$ & $0.3(35 / 11,915)$ & $<0.001$ \\
\hline$>=25$ & $4.2(25 / 589)$ & $1.9(11 / 589)$ & $<0.001$ & $0.8(30 / 3753)$ & $0.2(7 / 3753)$ & $<0.001$ \\
\hline \multicolumn{7}{|l|}{ Race/Ethnicity } \\
\hline White & $3.9(96 / 2442)$ & $1.0(24 / 2442)$ & $<0.001$ & $0.7(63 / 9604)$ & $0.2(24 / 9604)$ & $<0.001$ \\
\hline African-American & $11.2(272 / 2429)$ & $1.9(47 / 2429)$ & $<0.001$ & $3.0(166 / 6176)$ & $0.3(20 / 6176)$ & $<0.001$ \\
\hline Other ${ }^{a}$ & $5.1(86 / 1692)$ & $1.0(17 / 1692)$ & $<0.001$ & $0.8(44 / 5420)$ & $0.3(16 / 5420)$ & $<0.001$ \\
\hline \multicolumn{7}{|l|}{ Marital Status } \\
\hline Single & $7.4(384 / 5171)$ & $1.2(64 / 5171)$ & $<0.001$ & $1.3(203 / 15,316)$ & $0.3(46 / 15,316)$ & $<0.001$ \\
\hline Married & $5.0(63 / 1256)$ & $1.7(21 / 1256)$ & $<0.001$ & $1.2(61 / 5093)$ & $0.3(14 / 5093)$ & $<0.001$ \\
\hline Other ${ }^{b}$ & $5.1(12 / 234)$ & $1.3(3 / 234)$ & $<0.001$ & $1.2(11 / 1120)$ & $0.2(2 / 1120)$ & 0.011 \\
\hline \multicolumn{7}{|l|}{ Military rank } \\
\hline Enlisted & $7.2(449 / 6263)$ & $1.3(83 / 6263)$ & $<0.001$ & $1.4(266 / 18,862)$ & $0.3(59 / 18,862)$ & $<0.001$ \\
\hline Officers & $2.5(10 / 400)$ & $1.2(5 / 400)$ & $<0.001$ & $0.4(10 / 2676)$ & $0.1(3 / 2676)$ & $<0.001$ \\
\hline
\end{tabular}

BV Bacterial vaginosis. ${ }^{a}$ Other: Hispanic, American Indian/Alaskan Native, Asian/Pacific Islander, and others, ${ }^{\mathrm{b}}$ Other: Divorced, widowed, and others

${ }^{c}$ At least one episode

(Model 2). With respect to genital herpes and trichomoniasis, although these STIs were positively associated with repeat chlamydia diagnoses, their HRs were not significant in univariate and multiple analyses.

An analysis stratified by the number of repeat gonorrhea diagnoses indicated that, among the 735 women with gonorrhea, 561 had one diagnosis, 142 two diagnoses, 23 three diagnoses, and 9 four or more diagnoses. For each additional diagnosis of gonorrhea, the hazard of repeat chlamydia diagnosis increased significantly by 58\% (95\% CI: 44-73\%). After controlling for age, race/ ethnicity, marital status, and military rank, the adjusted hazard for repeat chlamydia was 46\% (95\% CI: 33-60\%).

\section{Discussion}

The findings from this large retrospective cohort analysis revealed a high incidence of repeat chlamydia, and that gonorrhea and BV were significant predictors associated with repeat chlamydia among U.S. Army women.

Our estimated repeat chlamydia rate (8 diagnoses per 100 py) was higher than that reported by Barnett and Brundage [5] (6 diagnoses per 100 py) and lower compared to Hakre et al [6] (16 diagnoses per 100 py). Some methodological differences in the design and analysis may explain these differences. First, the above studies determined the rate of recurrence to the first diagnosis, ignoring all subsequent diagnoses. Second, Barnett and Brundage [5] used only one ICD-9 code (099.41) to identify chlamydia diagnoses. Finally, we excluded approximately $25 \%$ of women with a history of STI, which may have affected our estimates given that an STI history is a predictor for repeat chlamydia [3, 16]. Nonetheless, these studies indicate a high rate of repeat chlamydia among U.S. Army women.

Table 3 Unadjusted and adjusted hazard ratios for repeat chlamydia diagnoses among U.S. Army women

\begin{tabular}{|c|c|c|c|c|c|c|}
\hline \multirow[t]{2}{*}{ Feature } & \multicolumn{2}{|c|}{ Unadjusted } & \multicolumn{2}{|c|}{ Adjusted Model $1^{a}$} & \multicolumn{2}{|c|}{ Adjusted Model $2^{b}$} \\
\hline & Crude $H R$ & $95 \% \mathrm{Cl}$ & Adjusted HR & $95 \% \mathrm{Cl}$ & Adjusted HR & $95 \% \mathrm{Cl}$ \\
\hline Gonorrhea & 1.58 & $1.44,1.73^{*}$ & 1.47 & $1.34,1.62^{*}$ & 1.46 & $1.33,1.60^{*}$ \\
\hline Bacterial vaginosis & 1.40 & $1.09,1.79^{* *}$ & 1.32 & $1.03,1.69^{* *}$ & 1.31 & $1.04,1.68^{* *}$ \\
\hline Genital herpes & 1.13 & $0.55,2.29$ & 1.04 & $0.53,2.04$ & 1.03 & $0.52,2.06$ \\
\hline Trichomoniasis & 1.43 & $0.43,4.68$ & 1.16 & $0.35,3.88$ & 1.13 & $0.34,3.75$ \\
\hline At least one of above & 1.69 & $1.53,1.88^{*}$ & 1.54 & $1.39,1.71^{*}$ & 1.53 & $1.38,1.69^{*}$ \\
\hline
\end{tabular}

${ }^{a}$ Adjusted for age (years); ${ }^{b}$ Adjusted for age (years), race/ethnicity, marital status, and military rank. ${ }^{*} P<0.001 ;{ }^{* *} P<0.05$ 
It was also observed that the highest repeat chlamydia rates occurred among young women (17-19 years), African-Americans, and single women. These observations are consistent with the literature [3]. In a study of 38,866 women, Hillis et al [8] reported that younger age ( $<20$ years) was a strong predictor for repeat chlamydia. A secondary data analysis from a large trial also determined that black women were at high risk of repeat chlamydia [17]. Additionally, a retrospective cohort study reported that single women had 1.60 times the risk of repeat chlamydia compared to married women [16]. In addition, the finding that enlisted personnel, compared to officers, had a higher rate of repeat chlamydia has been previously reported in the military literature $[5,7]$.

The analysis also revealed that the percentage of gonorrhea among women with repeat chlamydia was higher compared to women without repeat chlamydia. This finding suggests that, despite the decrease in the annual gonorrhea rates among women SMs during the study period [2], this bacterial STI has an impact on the burden of chlamydia. Similarly, BV was more prevalent among women with repeat chlamydia than women without repeat chlamydia. Interestingly, we found that, compared to single women, married women had a higher percentage of $\mathrm{BV}$. While this observation contradicts the literature on $\mathrm{BV}$, the higher incidence may be associated with a higher frequency of vaginal intercourse among married women. Based on the studies of Leppäluoto et al [18] and Vallor et al [19], who reported that higher frequencies of vaginal intercourse cause loss of hydrogen peroxide and replacement of the dominant lactobacilli microbiota by G. vaginalis before and after intercourse, Verstraelen et al [20] have argued that the associated risk factors for BV (e.g., multiple sexual partners) are proxy variables to the true risk exposure, which is the frequency of vaginal intercourse.

In our study, gonorrhea was the strongest diagnostic predictor for repeat chlamydia. Two large studies have documented that women with gonorrhea are at increased risk of recurrent chlamydia [8, 21]. In both studies, gonorrhea was evaluated at the time of initial chlamydia infection, and therefore, their results represent the risk of coinfection. Moreover, their analyses ignored the correlation between repeat events. If this correlation is ignored, the confidence intervals for the regression coefficients can be biased [22]. By contrast, in our analyses, gonorrhea was treated as a time-varying covariate, which is an appropriate approach to study repeated events. To help better understand the association between gonorrhea and repeat chlamydia, coinfected women or women with a history of gonorrhea before the initial chlamydia diagnosis were excluded from analysis. Our results strengthen the evidence that gonorrhea and repeat chlamydia are associated.
Additionally, we found that a diagnosis of BV was a predictor for repeat chlamydia among U.S. Army women. Although several studies have indicated an association between BV and chlamydia, including a recent large military study published by the authors [23], no study in the STI literature has reported that BV is associated with an increased risk of repeat chlamydia. This finding needs to be confirmed in further studies. There is ongoing debate as to whether BV is an STI or is simply a sexually enhanced disease [20]. The mechanisms for the relationship between chlamydia and BV are unclear given the lack of a definitive etiologic agent for this condition. With respect to genital herpes and trichomoniasis, it was not possible to obtain reliable HR estimates due to the small number of women with these STIs. Whether or not the burden of genital herpes and trichomoniasis is, in fact, low among female chlamydia "repeaters" in the U.S. Army should be confirmed through further research.

In military STI research, there are studies suggesting that risky sexual behaviors such as inconsistent condom use, having many sexual partners, unwanted sexual contact, and engaging in sex under the influence of alcohol are risk factors associated with chlamydia among women SMs $[24,25]$. However, there is a lack of information on what sexual risk behaviors are related to repeat chlamydia. Due to limitations of the DMSS data (e.g., no collection of data on sexual behaviors), it is not possible to determine whether repeat chlamydia diagnoses is due to reinfection either from an infected new sexual partner or from an untreated pre-existing sexual partner. Considering that U.S. Army women are predominantly young and are more likely to engage in high-risk sexual behaviors, it is plausible to consider that repeat chlamydia infections are influenced, to a significant extent, by reinfection from an untreated sexual partner, either civilian or military.

Identification of the risk predictors for initial and repeat chlamydia will help with clinical STI prevention and intervention efforts. Our findings contribute to the growing body of literature that is useful to clinicians while offering advice to female SMs with chlamydia; female SMs need to be retested 3 months after completion of treatment, regardless of whether their sexual partners were treated. This suggestion is consistent with the CDC's recommendations. In addition, chlamydia "repeaters" should receive comprehensive sex education and risk reduction counselling (e.g., consistent and correct usage of condoms) during their health care visits to prevent further reinfection. Additionally, chlamydia "repeaters" should be educated that this common infection is associated with adverse reproductive health outcomes, such as preterm birth and gynecological complications, including pelvic inflammatory disease. Further, it is useful for the U.S. Army authorities to determine whether military physicians are following the CDC's recommendations for chlamydia and other common STIs. 
In the field of STIs, several studies have reported that the clinical practice of treating the sexual partners of patients diagnosed with chlamydia, also known as expedited partner therapy (EPT), has reduced the incidence of reinfections [26]. However, to date, the U.S. military has not implemented this evidence-based approach for the management of chlamydia, gonorrhea, or any STI [27]. In part, this is due to the need for establishing close coordination with local civilian health departments because service members may have civilian partners. In addition, other medical and legal issues relating to the implementation of a military EPT program require consideration.

This study had some limitations. First, as mentioned previously, due to the absence of sexual behavior data (e.g., number of sexual partners) or travel-related risks in the DMSS, our estimates are subjected to confounding bias, which is an inherent problem of utilizing data from electronic medical systems. Second, the length of follow-up in our study may have impacted the number of repeat chlamydia diagnoses. Third, because gonorrhea and chlamydia are mostly asymptomatic among women, it is possible that the burden of repeat chlamydia in our population is underestimated. Fourth, the DMSS data cannot be utilized to determine whether repeat chlamydia is due to treatment failure, and therefore, over-reporting of chlamydia diagnoses is possible; the estimated cure rate of azithromycin and doxycycline for C. trachomatis is $97 \%$ and $98 \%$, respectively [28]. Fifth, although the U.S. military follows the CDC's STI treatment guidelines, it was not possible to determine whether antibiotic treatment for chlamydial and gonococcal infections was consistent during the study period. Lastly, the associations may be biased due to misclassification of BV and trichomoniasis by employing the Amsel criteria method and wet mount inspection, respectively. Despite these limitations, we provide evidence for additional clinical research and generate new hypotheses for further military investigation.

\section{Conclusions}

Based on the DMSS data and Andersen-Gill regression analysis, gonorrhea and BV were significant predictors for repeat chlamydia diagnoses among U.S. Army women during the 2006-2012 study period. Women personnel with repeat chlamydia represent a major reservoir for the ongoing transmission of infection, and reinfection increases the risk of further medical and reproductive complications. Our findings can guide military authorities in developing STI prevention programs to reduce the burden of "repeat" chlamydia infection in the U.S. military. As the U.S. Army has a population composed of members from differing cultural and socioeconomic backgrounds, culturally appropriate sex education programs are required and may be beneficial in terms of public health.

\section{Abbreviations}

BV: Bacterial vaginosis; DMSS: Defense Medical Surveillance System; ICD9: International Classification of Diseases, version 9; NAATs: Nucleic acid amplification tests; STI: Sexually transmitted infection

\section{Acknowledgements}

The authors thank Dr. Angelia Cost at the Epidemiology and Analysis section of the U.S. Armed Forces Health Surveillance Branch (AFHSB) for DMSS

database extraction and Sebastian-Santiago for technical assistance.

\section{Funding}

This study was funded by the AFHSB and its Global Emerging Infectious Surveillance section. The funder had no role in the study design, data analysis, interpretation of findings, or in the writing and publication of this report.

\section{Availability of data and materials}

The datasets generated and analyzed during the study are not publicly available. The study was approved by scientific review and institutional review boards at Lancaster University and the Walter Reed Army Institute of Research.

\section{Disclaimer}

The views expressed herein are those of the authors and do not reflect the official policy or position of the Department of the Army, Department of Defense, the U.S. Government, or any organization listed. At the time of this study, EKW was an employee of the US government and JLS was a contractor. This work was prepared as part of their official duties and, as such, there is no copyright to be transferred. This manuscript was approved for publication by the Defense Health Agency, the Office of the Assistance Secretary of Defense for Health Affairs, as well as by the DoD's Office of Prepublication and Security Review.

\section{Authors' contributions}

$\mathrm{CB}$ and EW conducted the investigation and prepared the manuscript. WS, $\mathrm{BH}$, and JS conceptualized the review and gave valuable comments and suggestions. All authors read and approved the final manuscript.

\section{Consent for publication}

Not applicable.

\section{Competing interests}

The authors declare that they have no competing interests.

\section{Author details}

${ }^{1}$ Division of Health Research, Lancaster University, Lancaster, UK. ${ }^{2}$ Walter Reed Army Institute of Research, Silver Spring, MD, USA. ${ }^{3}$ Senior Research Consultant, Washington, DC, USA. ${ }^{4}$ Armed Forces Health Surveillance Branch, Public Health Division, Defense Health Agency, Silver Spring, MD, USA.

Received: 26 March 2018 Accepted: 9 October 2018

Published online: 30 October 2018

\section{References}

1. CDC. Reported cases of sexually transmitted diseases in the rise, some at alarming rate. Accessed at http://www.cdc.gov/nchhstp/newsroom/2015/ std-surveillance-report-press-release.html.

2. AFHSC. Sexually transmitted infections, active component, U.S. armed forces, 2000-2012. MSMR. 2013;20:5-10.

3. Hosenfeld CB, Workowski KA, Berman S, Zaidi A, Dyson J, Mosure D, et al. Repeat infection with chlamydia and gonorrhea among females: a systematic review of the literature. Sex Transm Dis. 2009;6:478-89.

4. Orr DP, Johnaton K, Brizendine E, Kartz B, Forterenberry JD. Subsequent sexually transmitted infection in urban adolescents and young adults. Arch Pediatr Adolesc Med. 2001;155:947-53.

5. Barnett $S$, Brundage J. Incidence of recurrent diagnoses of chlamydia trachomatis genital infections among male and female soldiers of the US Army. Sex Transm Infect. 2001;77:33-6.

6. Hakre S, Oyler RJ, Ferrell KA, Li F, Michael NL, Scott PT, et al. Chlamydia trachomatis infection rates among a cohort of mobile soldiers stationed at Fort Bragg, North Carolina, 2005-2010. BMC Public Health. 2014;14:181. 
7. Owings AJ, Clark LL, Rohrbeck P. Incident and recurrent chlamydia trachomatis and Neisseria gonorrhoeae infections, active component, U.S. armed forces, 2010-2014. MSMR. 2006;23:20-8.

8. Hillis SD, Nakashima A, Marchbanks PA, Addiss DG, Davis JP. Risk factors for recurrent chlamydia trachomatis infections in women. Am J Obstet Gynecol. 1994;170:801-6.

9. Rubertone MV, Brundage JF. The defense medical surveillance system and the department of defense serum repository glimpses of the future of public health surveillance. Am J Public Health. 2002;92:1900-4.

10. Lee SE, Nauschuetz W, Jordan N, Lindler L, Steece R, Pfau E, et al. Survey of sexually transmitted disease laboratory methods in US Army laboratories. Sex Transm Dis. 2010;37:44-8.

11. Leamer NK, Jordan NN, Pacha LA, Latif NH, Garges EC, Gaydos JC. Survey of sexually transmitted disease laboratory methods in US army laboratories, 2012. Mil Med. 2017:182:1726-32.

12. Morré $S A$, Sillekens $P$, Jacobs MV, van Aarle $P$, de Blok $S$, van Gemen B, et al. RNA amplification by nucleic acid sequence-based amplification with an internal standard enables reliable detection of chlamydia trachomatis in cervical scrapings and urine samples. J Clin Microbiol. 1996;34:3108-14.

13. CDC. De-duplication guidance for gonorrhea and chlamydia laboratory reports. Retrieved from https://www.cdc.gov/std/laboratory/de-duplicationguidance-june2016.pdf.

14. Andersen PK, Gill RD. Cox's regression model for counting processes: a large sample study. Ann Stat. 1982;10:1100-20.

15. Moulton LH, Dibley MJ. Multivariate time-to-event models for studies of recurrent childhood diseases. Int J Epidemiol. 1997:26:1334-9.

16. Newman LM, Warner L, Weinstock HS. Predicting subsequent infections in patients attending sexually transmitted disease clinics. Sex Transm Dis. 2006; 33:737-42.

17. Peterman $T A$, Tian $L H$, Metcalf $C A$, Satterwhite $C L$, Malotte $C K$, DeAugustine $\mathrm{N}$, et al. High incidence of new sexually transmitted infections in the year following a sexually transmitted infection: a case for rescreening. Ann Intern Med. 2006;145:564-72.

18. Leppäluoto PA. Autopsy of bacterial vaginosis: a physiological entity rather than a contagious disease. Acta Obstet Gynecol Scand. 2008;87:578-9.

19. Vallor AC, Antonio MA, Hawes SE, Hillier SL. Factors associated with acquisition of, or persistent colonization by, vaginal lactobacilli: role of hydrogen peroxide production. J Infect Dis. 2001;184:1431-6.

20. Verstraelen $H$, Verhelst $R$, Vaneechoutte $M$, Temmerman $M$. The epidemiology of bacterial vaginosis in relation to sexual behavior. BMC Infect Dis. 2010;10:81.

21. Xu F, Schillinger JA, Markowitz LE, Sternberg MR, Aubin MR, St Louis ME. Repeat chlamydia trachomatis infection in women: analysis through a surveillance case registry in Washington state, 1993-1998. Am J Epidemiol. 2000;152:1164-70.

22. Twisk JW, Smidt N, de Vente W. Applied analysis of recurrent events: a practical overview. J Epidemiol Community Health. 2005;59:706-10.

23. Bautista CT, Wurapa E, Sateren WB, Morris SM, Hollingsworth BP, Sanchez JL. Association of bacterial vaginosis with chlamydia and gonorrhea among women in the U.S. Army. Am J Prev Med. 2017:52:632-9.

24. Stahlman S, Javanbakht M, Cochran S, Hamilton AB, Shoptaw S, Gorbach PM. Self-reported sexually transmitted infections and sexual risk behaviors in the U.S. military: how sex influences risk. Sex Transm Dis. 2014;41:359-64.

25. Gaydos CA, Howell MR, Quinn TC, McKee KT Jr, Gaydos JC. Sustained high prevalence of chlamydia trachomatis infections in female army recruits. Sex Transm Dis. 2003;30:539-44.

26. Mmeje O, Wallet S, Kolenic G, Bell J. Impact of expedited partner therapy (EPT) implementation on chlamydia incidence in the USA. Sex Transm Infect. 2017; pii: sextrans-2016-052887. https://doi.org/10.1136/sextrans-2016 052887 [Epub ahead of print].

27. Stidham RA, Garges EC, Knapp SA. Expedited partner therapy to combat Neisseria gonorrhoeae and chlamydia trachomatis in military populations: can we apply this best practice? Mil Med. 2015;180:876-81.

28. Lau CY, Qureshi AK. Azithromycin versus doxycycline for genital chlamydial infections: a meta-analysis of randomized clinical trials. Sex Transm Dis. 2002:29:497-50

Ready to submit your research? Choose BMC and benefit from:

- fast, convenient online submission

- thorough peer review by experienced researchers in your field

- rapid publication on acceptance

- support for research data, including large and complex data types

- gold Open Access which fosters wider collaboration and increased citations

- maximum visibility for your research: over $100 \mathrm{M}$ website views per year

At BMC, research is always in progress.

Learn more biomedcentral.com/submissions 